\title{
Destination image on the DMO's platforms: official website and social media
}

\author{
Imagen del destino en las plataformas de la OGD: sitio web oficial y medios sociales
}

\author{
Sebastian Molinillo \\ University of Malaga, Faculty of Economics and Business, Department of Business Management, Campus El Ejido, 29013 Malaga (Spain), \\ smolinillo@uma.es \\ Francisco Liébana-Cabanillas \\ University of Granada, Department of Marketing and Market Research, 18011 Granada (Spain), \\ franlieb@ugr.es \\ Rafael Anaya-Sánchez \\ University of Malaga, Faculty of Economics and Business, Department of Business Management, Campus El Ejido, 29013 Malaga (Spain), \\ rafael.anaya@uma.es
}

\begin{abstract}
Tourists usually configure and develop ideas about possible destinations based on information previously gathered from both social media and the official web of the destination management organization (DMO). In spite of the relevance of said information sources, there have not been many studies evaluating how these different sources influence the destination image. This research proposes a model intended to explain the image creation process of a destination taking into account both the DMO's online platforms and the perceived psychological distance. The proposed model is tested with an empirical study including a questionnaire which collects data from 264 participants. The validity of the model is reviewed through PLS analysis. Results show that the psychological distance does not influence the overall destination image. In addition, the overall destination image can be estimated to a larger extent when tourists approach social media as their main source of information. Implications and conclusions are discussed
\end{abstract}

Keywords: Destination image, psychological distance, tourism website, social media, DMO.

\section{Introduction}

Destination image is a variable which positively influences tourist destination, impacting first and subsequent trips (Baloglu \& McCleary, 1999; Beerli \& Martin; 2004; Rodríguez-Molina, FríasJamilena, \& Castañeda-García, 2015; Tan \& Wu, 2016). The image is defined as a mental representation, a set of beliefs, ideas, and impressions that people have of a destination (Crompton 1979). Psychological distance impacts the destination image formation process (Massara \& Severino, 2013; San Martin \& Rodriguez Del Bosque, 2008; Zhang, Seo, \& Lee, 2013). Psychological distance, which holds more relevance when tourists are not familiar with the destination or the local culture (Mackay \& Fesenmaier, 1997; Massara \& Severino, 2013; Ng, Lee, \& Soutar, 2007; Prentice, 2004), becomes an issue that the destination management organization (DMO) needs addressing in order to attract a larger number of tourists.

DMOs should try to recreate a sense of proximity and familiarity in the destination so its image becomes more attractive to potential tourists. For this purpose, DMOs use their official websites and also interact in social media (Hays, Page, \& Buhalis, 2013; Jeong, Holland, Jun, \& Gibson, 2012; Xiang \& Gretzel, 2010). Said online resources influence both the destination imagen and the decisions which tourists make (Llodrà-Riera, Martínez-Ruiz, Jiménez-Zarco \& Izquierdo-Yusta, 2015; Tan \& Wu, 2016). However, official online

\section{Resumen}

Los turistas se forman una imagen del destino teniendo en cuenta la información recibida a través de canales como los medios sociales y la web oficial de la Organización Gestora del Destino (OGD). A pesar de la relevancia de estos canales pocos trabajos han analizado las posibles diferencias en su influencia en la formación de la imagen. Adicionalmente, el efecto de la distancia psicológica en el proceso de construcción de la imagen del destino no ha sido suficientemente evaluado en un contexto online. En esta investigación se propone un modelo para explicar la formación de la imagen del destino en función de la fuente de información online empleada y de la distancia psicológica percibida. El modelo propuesto es contrastado con un estudio empírico con 264 encuestados, mediante un análisis PLS. Los resultados muestran que la distancia psicológica no influye en la imagen global del destino. Además, la imagen global del destino puede estimarse en mayor medida cuando los turistas abordan los medios sociales como su principal fuente de información. Se discuten las implicaciones y las conclusiones.

Palabras clave: Imagen del destino, distancia psicológica, sitio web oficial de turismo, medios sociales, OGD.

websites need a better and improved management (Del VastoTerrientes, Fernández-Cavia, Huertas, Moreno, \& Valls, 2015). Also, the impact of social media on the destination image has not been thoroughly analyzed (Kladou \& Mavragani, 2015; Költringer \& Dickinger, 2015; Mariani, Di Felice, \& Mura, 2016; Munar \& Jacobsen, 2014). In addition, only a few studies have focused on the influence of different online information sources on distant destination image (Marlow \& Dabbish, 2014).

The aim of this study is to enrich knowledge in the existing literature regarding these findings by assessing the moderating effect of the DMOs' online platforms (official websites and social media) and also the impact of the psychological distance variable on the overall destination image. This study develops a model based on the image theory (Myers, 1968) and the consequent implementations in the tourism sector (Baloglu \& McCleary, 1999; Dichter, 1985; Lin, Morais, Kerstetter, \& Hou, 2007) by incorporating the impact of the psychological distance (Liberman, Trope, \& Stephan, 2007; Massara \& Severino, 2013; Trope, Liberman, \& Wakslak, 2007). Overall destination image is approched in this study using a model which takes into account both cognitive and affective dimensions, which moderate the impact of the psychological distance variable. In addition, this study focuses on the moderating effect of the different sources of online information tourists might approach by making a distinction between the official websites of the DMOs and their presence in 
the social media. This research aims to test and validate the proposed model in order to contribute to the destination image formation process knowledge within an online context.

In that regard, this study is divided and structured into four parts. The first part focuses on the literature review and the suggested research hypotheses. Later on, this study describes both the methodology employed and the results obtained. Finally, implications and conclusions are drawn and discussed from a theoretical point of view and also within a real-world experience context.

\section{Literature review and hypotheses}

\subsection{Psychological distance}

Destination image is a construct widely explored in different studies concerning the tourism sector since it directly influences the intention to travel for the first time or travel again to a certain destination and also impacts tourists' suggestions about said destinations (Kim \& Stepchenkova, 2015; Tan \& Wu, 2016; Tasci \& Gartner, 2007). The Image Theory suggests that the world is a psychological or inaccurate representation of an objective reality existing in the mind of the individual (Myers, 1968). The destination image is described as a mental representation involving beliefs, ideas, impressions, prejudices, knowledge and feelings which an individual might have regarding a tourist destination (Baloglu \& McCleary, 1999; Crompton, 1979; Driscoll, Lawson, \& Niven, 1994). Thus, it can be considered as a subjective interpretation an individual might have (Agapito, Valle, $\&$ Mendes, 2013), influenced by the information previously gathered from different sources and agents before the actual first trip (FríasJamilena, Rodríguez-Molina, \& Castañeda-Garcia, 2008).

The destination image formation process in the mind of the tourists can be influenced by the psychological distance construct. The psychological distance can also be used as a measurement of the ability of a certain individual to either abstractly or essentially evoke a distant event, place or object since direct interaction is not possible (Liberman et al., 2007; Trope et al., 2007). The psychological distance that consumers perceive regarding the tourism product impacts their decisions (Massara \& Severino, 2013; Trope et al., 2007; Zhang et al., 2013). Massara and Severino (2013) already thoroughly analyzed the way the psychological distance has been approached in the most relevant tourism journals. In their study, they incorporated and assessed constructs such as cultural distance and familiarity, noting that tourists possess a cognitive image of what they anticipate and expect from a certain destination they already know or they previously gathered information on. Their study concluded that cognitive images lead potential tourists to prefer destinations with a noticeable sense of familiarity and a manifest degree of relation to their culture. In this regard, tourists adjust more realistically their destinations images with a less marked psychological distance (MacKay \& Fesenmaier, 1997; Ng et al., 2007; Prentice, 2004). Ng et al. (2007) reviewed and analyzed studies published since the $80 \mathrm{~s}$ concerning the influence of cultural distance on the intention to visit, concluding that tourists are inclined to prefer destinations where the local culture, clearly exposed as part of the destination image, has a sense of familiarity and consistency with their own culture. The attitude of tourists can be limited by several factors such as the lack of familiarity of the destination, which in turn might lead to an overall poor image and view about the destination (Chen, Chen, \& Okumus, 2013). Tourists are likely to maintain a rather favorable cognitive and affective image regarding a certain destination when the cultural distance between them is low or negligible (San Martin \& Rodriguez del Bosque, 2008). Thus, perceived psychological distance can negatively influence the image tourists form about a particular destination (Marlow \& Dabbish, 2014). In this regard the following hypotheses are suggested:

H1. The higher the tourist's psychological distance, the lower his/her cognitive image.

H2. The higher the tourist's psychological distance, the lower his/her affective image.

\subsection{Tourism destination image formation process}

The matter of destination image dimensionality has divided the extant literature (Josiassen et al. 2015). According to Gartner (1994) the image formation process involves 3 components: cognitive, affective, and conative. "The cognitive component constitutes awareness: what someone knows or thinks they know about a destination. The affective component is based on how one feels about this knowledge. The conative component is the action step: how one acts on the information" (Konecnik \& Gartner, 2007, p.403). Some authors have considered the conative component as the response, reaction or feedback originated from the image, noted in the intention to visit the destination or discussing it among other possible reactions. Following the same reasoning, Baloglu \& McCleary (1999) described the overall destination image as an attitudinal construct incorporating both cognitive and affective components. In addition, according to San Martin \& Rodriguez del Bosque (2008), ahead of the first visit, tourists evaluate destinations based on cognitive and affective attributes. In this regard, this research considers the multiple components and concepts concerning the destination image (cognitive and affective components). Within the tourism sector context, severa variables such as perceived security, comfort, accessibility, and saturation intensity are considered cognitive factors (Beerli \& Martin, 2004; Smith, Li, Pan, Witte, \& Doherty, 2015), whereas variables such as the level of excitement, pleasure or self-discovery are considered affective factors (Walmsley \& Young, 1998).

A number of studies have supported the multi-dimensional implications of the destination image formation process based on the direct and positive influence of both cognitive and affective images (Lin et al., 2007; Mano \& da Costa, 2015; Smith et al., 2015; Tan \& Wu, 2016). In addition, the cognitive image directly and positively influences the affective image (Kim \& Stepchenkova, 2015; Mano \& da Costa, 2015; Tan \& Wu, 2016), since the affective image involves the personal and unique reactions and feedback which an individual has regarding collected and reviewed information about a certain destination (Smith et al., 2015). The cognitive image positively influences the affective image, forming together the overall destination image. Accordingly, this study suggests the following hypotheses:

H3. The higher the tourist's cognitive image, the higher his/her overall destination image.

H4. The higher the tourist's cognitive image, the higher his/her destination affective image.

H5. The higher the tourist's affective image, the higher his/her overall destination image. 
2.3 Social Media and official websites relevance in destination image formation process

Internet is a highly valuable tool and a major asset regarding tourism products, both official websites and social media are keys during the destination image formation process. The DMO uses the official website for brand building, promoting their products and making information available for tourists (Fernández-Cavia, Rovira, Diaz-Luque, \& Cavaller, 2014) while developing a positive destination image (Llodrà-Riera et al., 2015; Tan \& Wu, 2016). The official website of the DMO impacts the overall destination image to a greater extent compared to websites of travel agents and other business partners (Choi, Lehto, \& Morrison, 2007). A well planned official website positively influences the overall destination image (Jeong et al., 2012; Rodríguez-Molina et al., 2015), even helping to overcome cultural barriers (Moura, Gnoth, \& Deans, 2014) and inciting a higher intention to visit (Chung, Lee, Lee \& Koo, 2015). However, Del Vasto-Terrientes et al. (2015) suggest that three parameters should generally be improved: official website, usability, accessibility, and destination brand image.

DMOs also take advantage of social media in order to improve destination image thanks to a more interactive and welcoming communication promoting user participation (Lim, Chung, \& Weaver, 2012; Marlow \& Dabbish, 2014). The User Generated Content (UGC) takes on many different forms, such as text, status updates, videos, pictures, as well as consumer-produced product reviews and advertisements (Smith, Fischer, \& Chen, 2012). The UGC influences tourists' decisions regarding destinations (LlodràRiera et al., 2015). Furthermore, Social media such as Facebook, Youtube and Instagram have become widely spread and commonplace among tourists thanks to their ease of use, reach, scope and enjoyment (Ayeh, Au, \& Law, 2013). Content generated through these media has a higher level of trust among users since the business opportunities lingering behind them are blurried and not outright clear (Fotis, Buhalis, \& Rossides, 2012). Social media are the richest and most diverse source of online information (Költringer \& Dickinger, 2015), offering comprehensive and useful information for those participants who sometimes published tourist information on the Internet (Llodra-Riera et al., 2015). Further improving destination image thanks to tourist's participation (Lyu, 2016), even in problematic contexts (Avraham, 2015). However, perceived destination image might change depending on the publisher of the information, be it the DMO or the tourists themselves (Lim et al., 2012; Stepchenkova \& Zhan, 2013).

In the literature, several authors suggest that user generated content is mainly originated from cognitive reasons (Kladou \& Mavragani, 2015; Tseng, Wu, Morrison, Zhang, \& Chen, 2015). In addition, this content also targets and affects the senses and feelings of the users (Xiong, Hashim, \& Murph, 2015). Audiovisual content impacts the destination image to the greatest extent (Munar \& Jacobsen, 2014). Also, since the information available is vastly richer, social media also help successfully overcoming the issues associated with the psychological distance variable compared to the rest of online platforms and resources (Marlow \& Dabbish, 2014). In light of all of the above findings, the type of online media considered by the DMO to provide information about the destination definitely influences the way users perceive the destination image. In this regard, this study proposes the following hypotheses:

H6. The DMO's online platform will moderate the structural relationships among psychological distance, cognitive image, affective image, and overall image.

H6a. DMO's online platform will moderate the effect of psychological distance on cognitive image.

H6b. DMO's online platform will moderate the effect of psychological distance on affective image.

H6c. DMO's online platform will moderate the effect of cognitive image on affective image.

H6d. DMO's online platform will moderate the effect of cognitive image on destination image.

H6e. DMO's online platform will moderate the effect of affective image on destination image.

Figure 1 below shows the suggested model where psychological distance influences the destination image formation process.

Figure 1: Research Model

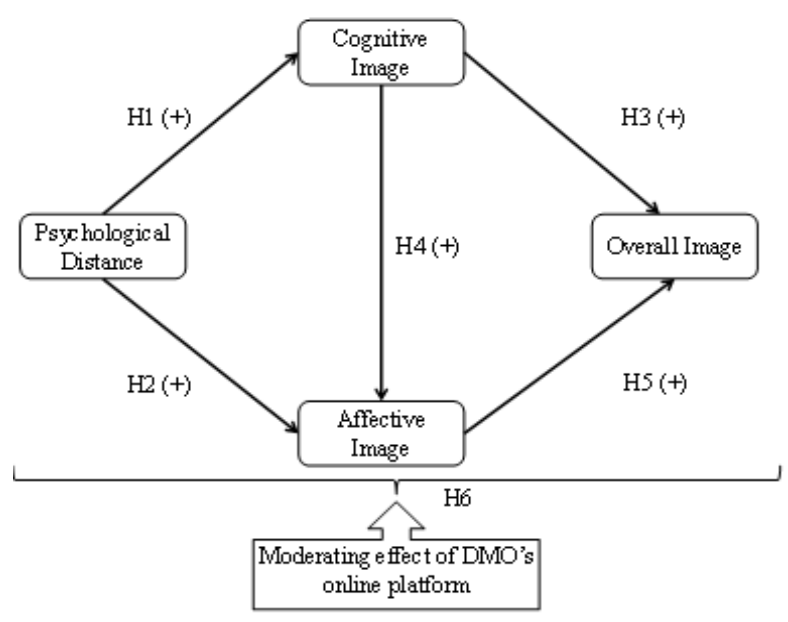

Source: Authors. 


\section{Methodology}

\subsection{Experimental design}

Empirical data used in this research were collected conducting an experiment involving four samples from a Spanish college. Information about a certain DMO was exposed to participants in each sample using one DMOs online platform: official website, Facebook, Youtube or Instagram accounts. It is important to note that social media sites employed for data collection in this research are among the most widely used in Spain (Association for Media Research [AIMC, 2015). During the experiment, a focus group of students identified an unusual, non-familiar destination for the population. The selected destination was Indonesia. The choice of this destination was confirmed valid for this research since both the official website (www.indonesia.travel) and social media resources (Facebook: www.facebook.com/indonesiatravel; Instagram: https://instagram.com/indtravel/; Youtube: https://www.youtube.com/user/theindonesiatravel) were available and updated.

The sampling procedure was a convenience sampling. However, participants had to meet 3 different criteria: i) Frequent social media and Internet usage; ii) Traveling abroad (outside country of origin) at least once during the last year; iii) The destination chosen for this research should not be familiar to them. Control questions suggested by Jeong et al. (2012) and Marlow and Dabbish (2014) serve to verify that no participant in any of the samples has any sort of beforehand experience with the destination. Data collection was performed in March, 2016. This research involved a total number of 265 participants, divided into four groups of similar size; each group include more than the bare minimum of 45 participants as previously suggested in the literature (Kim, Kim, \& Wise, 2014) for studies regarding social media browsing analysis.

Sample groups explored a different online platform in research sessions conducted in the tech labs of the college. Online platforms were assigned to each group beforehand. Regarding research methodology, the same procedure is carried in every research session: firstly, participants were faced with screening questions to verify whether they had beforehand experience with the destination. Secondly, participants answered questions regarding tourism segmentation trends and habits, and explored their assigned online platform for a minimum period of 10 minutes. Then, they were asked questions regarding their browsing experience in the assigned platform. Finally, participants answered questions involving social demographic factors.

Characteristics relevant to the sample are shown in Table 1.

Table 1. Sample characteristics

\begin{tabular}{|l|r|r|}
\hline Variable & Frequency & Percentage \\
\hline Gender & & \\
\hline Male & 123 & $46.42 \%$ \\
\hline Female & 142 & $53.58 \%$ \\
\hline Age & & \\
\hline $18-24$ & 237 & $89.43 \%$ \\
\hline $25-34$ & 27 & $10.19 \%$ \\
\hline over 35 & 1 & $0.38 \%$ \\
\hline Daily social media usage & & \\
\hline Less than 30 minutes & 45 & $16.98 \%$ \\
\hline 30 minutes to 1 hour & 70 & $26.42 \%$ \\
\hline 1 h. to 2 hrs. & 71 & $26.79 \%$ \\
\hline 2 hrs. to 3 hrs. & 46 & $17.36 \%$ \\
\hline Above 3 hrs. & 33 & $12.45 \%$ \\
\hline
\end{tabular}

Source: Authors.

\subsection{Measurement of variables}

Variables were measured according to validated scales from previous studies. The psychological distance variable was measured through 4 items already suggested by Zhang et al. (2013). A Likert scale of 7 points was also employed. Each item exemplified one of the following 4 dimensions: language differences, economic condition differences, political system differences and, finally, cultural distance. The method to assess the cognitive image variable was adapted from Smith et al. (2015) and four bipolar items were used for measurement (rather hostile/friendly, unsafe /relaxing, accessible/isolated, stagnant/lively, quiet/noisy, overcrowded/sparse). The affective image variable was also measured with four bipolar items (sad/fascinating, peaceful/exciting, ugly/pretty, uneasy/relaxing) already suggested by Lin et al. (2007). Finally, to measure the overall destination image variable this research asked a single question to participants, as previously suggested by Lin et al. (2007) and Smith et al. (2015).

\section{Results}

\subsection{Measurement Model}

In order to comprehensively analyze collected data, the partial least square (PLS) method was employed using Smartpls 3 software within an structural equation model (SEM) path (Ringle, 
Wende, \& Becker, 2015). The precision of the measurement tools regarding the lack of random errors (showing the reliability of both items and scales) in the ending results is key when assessing the measurement model. Also, assessing the values obtained and estimating the degree to which measures relate to scales and reflect the actual differences between objects and the traits being measured (convergent and discriminant validation).
Individual reliability of items is assessed by examining the simple correlation of the different indexes regarding their respective variables. Values higher than 0.7 imply that the shared variance between the construct and its indexes is higher than the common error variance (Barclay, Higgins, \& Thompson, 1995). In this research, results obtained show values higher than those recommended in the literature (Table 2).

Table 2: Evaluation of the measurement model: CR, composite reliability, AVE, extracted variance

\begin{tabular}{|l|c|c|c|}
\hline Construct & Cronbach's Alpha & CR & AVE \\
\hline Psychological Distance & 0.581 & 0.826 & 0.704 \\
\hline Cognitive Image & 0.723 & 0.827 & 0.548 \\
\hline Affective Image & 0.814 & 0.878 & 0.643 \\
\hline Overall Image & 1 & 1 & 1 \\
\hline & $\begin{array}{c}\text { Note. } * * * \\
\text { Source: Authors. }\end{array}$ & & \\
\hline
\end{tabular}

The reliability of the variables determines items' reliability and accuracy when measuring the same latent variable (internal consistency). In order to approach this, it is calculated Cronbach's Alpha coefficient (Cronbach, 1951) and the factor's compound reliability (CR) (Nunnally \& Bernstein, 1994). The minimum recommended value in order to properly measure and assess the reliability of scales through Cronbach's Alpha is 0.7 (Cronbach, 1951). However, some authors suggest that, depending on certain factors (e.g. the number of items in the scale and the number of observations), the recommended value can indeed be lowered to some extent. In this regard, George and Mallery (1995), stated that a Cronbach's Alpha below 0.5 implies an unacceptable level of reliability. On the other hand, a value between 0.5 and 0.6 is considered poor. A value between 0.6 and 0.7 is regarded as a sign of weak reliability. A value between 0.7 and 0.8 can be considered acceptable. A value between 0.8 and 0.9 shows good reliability and, finally, a value higher than 0.9 indicates excellent reliability. Malhotra (1997) suggests that a value of 0.6 or higher can be considered acceptable. Regarding our research, all obtained values can be considered acceptable but the value concerning the psychological distance construct, which is in the threshold between poor and acceptable reliability.

In order to assess convergent validity, this research resorts to an analysis of the Average Variance Extracted (AVE) (Fornell \&
Larcker, 1981). This analysis method allows measurement of the degree of variance a construct obtains their indexes respecting the variance in measurement errors. In this study, the AVE value obtained is higher than the minimum value suggested $(0.5)$ in every construct.

Cross-loadings' of latent variables and observed variables regarding three items $(\mathrm{Cl} 2, \mathrm{PD} 2$ and $\mathrm{PD} 3)$ did not reach the suggested values. In light of this finding, they were removed from the model (Del Barrio \& Luque, 2012).

In order to properly assess the reliability of the discriminant validity through PLS analysis, this study reaches for three different methods: (i) the examination of cross-loadings of the indicators, according to Hair et al. (2014), requires that the loadings of each indicator on its construct are higher than the cross-loadings on other constructs (Table 3); (ii) the Fornell-Larcker criterion, analyzing correlations between the different dimensions and finding if their value is lower than the square root of the AVE value (Fornell \& Larcker, 1981) (Table 4); (iii) in addition, Henseler, Ringle and Sarstedt (2015) have recently suggested a third procedure where the value of the Heterotrait-Monotrait ratio of correlations (HTMT) between two constructs should be below 0.9. In this research, obtained values are a tad lower than those previously suggested.

Table 3: Discriminant validity and cross loads

\begin{tabular}{|c|c|c|c|c|}
\hline & Affective Image & Cognitive Image & Psychological Distance & Overall Image \\
\hline Al1 & 0.778 & 0.610 & 0.047 & 0.510 \\
\hline$A \mid 2$ & 0.852 & 0.596 & -0.091 & 0.465 \\
\hline Al3 & 0.842 & 0.622 & -0.035 & 0.445 \\
\hline Al4 & 0.730 & 0.516 & -0.090 & 0.382 \\
\hline Cl1 & 0.621 & 0.776 & -0.024 & 0.429 \\
\hline $\mathrm{Cl} 3$ & 0.485 & 0.769 & -0.005 & 0.350 \\
\hline $\mathrm{Cl} 4$ & 0.661 & 0.814 & 0.025 & 0.500 \\
\hline $\mathrm{Cl} 5$ & 0.333 & 0.580 & -0.075 & 0.350 \\
\hline PD1 & -0.045 & -0.014 & 0.865 & -0.062 \\
\hline PD4 & -0.037 & -0.016 & 0.811 & -0.040 \\
\hline OI & 0.565 & 0.558 & -0.061 & 1.000 \\
\hline
\end{tabular}

Source: Authors. 
Table 4: Discriminant validity. Fornell-Larcker criterion (below the main diagonal) and Heterotrait-Monotrait Ratio (HTMT) (above the main diagonal)

\begin{tabular}{|l|c|c|c|c|}
\hline & Affective Image & Cognitive Image & Psychological Distance & Overall Image \\
\hline Affective Image & $\mathbf{0 . 8 0 2}$ & 0.925 & 0.118 & 0.624 \\
\hline Cognitive Image & 0.734 & $\mathbf{0 . 7 4 0}$ & 0,075 & 0.648 \\
\hline Psychological Distance & $-0,049$ & $-0,018$ & $\mathbf{0 . 8 3 9}$ & 0.079 \\
\hline Overall Image & 0.565 & 0.558 & -0.061 & $\mathbf{1 . 0 0 0}$ \\
\hline
\end{tabular}

Note. Main diagonal: square root of the AVE.

Source: Authors.

\subsection{Structural model}

In order to assess the structural model, this research resorts in the first place to analyzing $R^{2}$ of all constructs involved, showing the variance of each construct as explained and supported in the model (Table 5). Falk and Miller (1992) stated that an adequate value should be 0.1 or higher. Regarding the suggested model in this study, all values are higher than 0.3 except the value for the cognitive image variable, which is borderline too low compared to the recommended minimum value.

Table 5: Evaluation of structural model (bootstrapping $=\mathbf{5 0 0}$ ).

\begin{tabular}{|c|c|c|c|}
\hline Relationship-construct & Path & $\mathbf{R}^{2}$ & $f^{2}$ \\
\hline $\mathrm{PD} \rightarrow \mathrm{Cl}$ & -0.018 & & 0.01 \\
\hline $\mathrm{PD} \rightarrow \mathrm{Al}$ & -0.036 & & 0.01 \\
\hline $\mathrm{Cl} \rightarrow \mathrm{Al}$ & $0.733 * * *$ & & \\
\hline $\mathrm{Cl} \rightarrow \mathrm{OI}$ & $0.311 * * *$ & & \\
\hline $\mathrm{Al} \rightarrow \mathrm{OI}$ & $0.337 * * *$ & & \\
\hline $\begin{array}{l}\text { Affective Image } \\
\text { Cognitive Image } \\
\text { Overall Image }\end{array}$ & & $\begin{array}{l}0.540 \\
0.000 \\
0.364\end{array}$ & \\
\hline
\end{tabular}

Source: Authors.

Secondly, this research explored standardized regression weights, showing the relative weight of the factors affecting endogenous variables. Chin (1998) suggested values higher than 0.3, however, values higher than 0.2 could be admitted in exploratory researches or when they are applied to several different sectors. Regarding the suggested model in this study, all relationships were evident and relevant showing values higher than those recommended but the value concerning the relationship between psychological distance and affective image, scoring lower than the recommended value.

The $\mathrm{f} 2$ ratio measures whether an independent latent variable has a substantial impact on a latent dependent variable; Coefficients $\mathrm{f} 2$ values between 0.02 and 0.15 , between 0.15 and 0.35 , and 0.35 or higher indicate that an exogenous latent variable has a small, medium or large effect respectively (Chin, 1998).

Finally, the value of the standardized root mean square residual (SRMR) (Henseler et al., 2015) allows assessing the difference between the observed correlation and the expected correlation as an adjustment measure for the proposed model. Since any value lower than 0.08 is considered valid, the obtained value of 0.07 is consequently measured as a correct adjustment for the proposed model.
In light of the obtained results, all the hypotheses in this study are considered supported since all of them have a significant importance except those related to the psychological distance variable. This is, psychological distance does not influence the image of the tourist destination nowadays. Regarding the model representation in this study, it is important to note the correct adjustment $(S R M R=0.06$ ) and the adequate values obtained from $R^{2}$ of the examined variables.

\subsubsection{Analyzing the moderating effect of the DMO's online platform}

Once both the measurement and structural models have been assessed, this study analyses the moderating effect of the sources of information separating them into two entities: official website and social media, as stated in hypothesis H6. Using the Henseler (2007) approach for multigroup comparison in coefficient pairs (PLS-MGA), this study confirms that the coefficients obtained for the relationship between the cognitive and affective images attain different values regarding the online platform (i.e. website or social media) involved in the analysis $(p<0.005)$ (table 6$)$. In this regard, the path coefficients of social media (0.783) are higher than those of the official website (0.548), implying that the relationship between these variables is more significant when tourists approach the DMO's presence and activities in social media. 
Table 6: PLS-MGA

\begin{tabular}{|l|c|c|}
\hline & Path Coefficients-diff (social media-official website) & p-Value (social media-official website) \\
\hline PD $\rightarrow$ Al & 0.077 & 0.295 \\
\hline PD $\rightarrow$ Cl & 0.304 & 0.937 \\
\hline $\mathrm{Cl} \rightarrow$ Al & 0.235 & 0.002 \\
\hline $\mathrm{Cl} \rightarrow$ OI & 0.028 & 0.588 \\
\hline $\mathbf{A l} \rightarrow$ OI & 0.107 & 0.258 \\
\hline
\end{tabular}

Source: Authors.

Results gathered from each of the suggested models show different values for $\mathrm{R}^{2}$ of the overall destination image variable. In the research model that involves social media as the source of information, $R^{2}$ has a value of 0.365 , opposed to the model approaching official websites as the source of information with a $R^{2}$ value of 0.243 (Figure 2).

Figure 2: Behavioral models official Website/Social Media

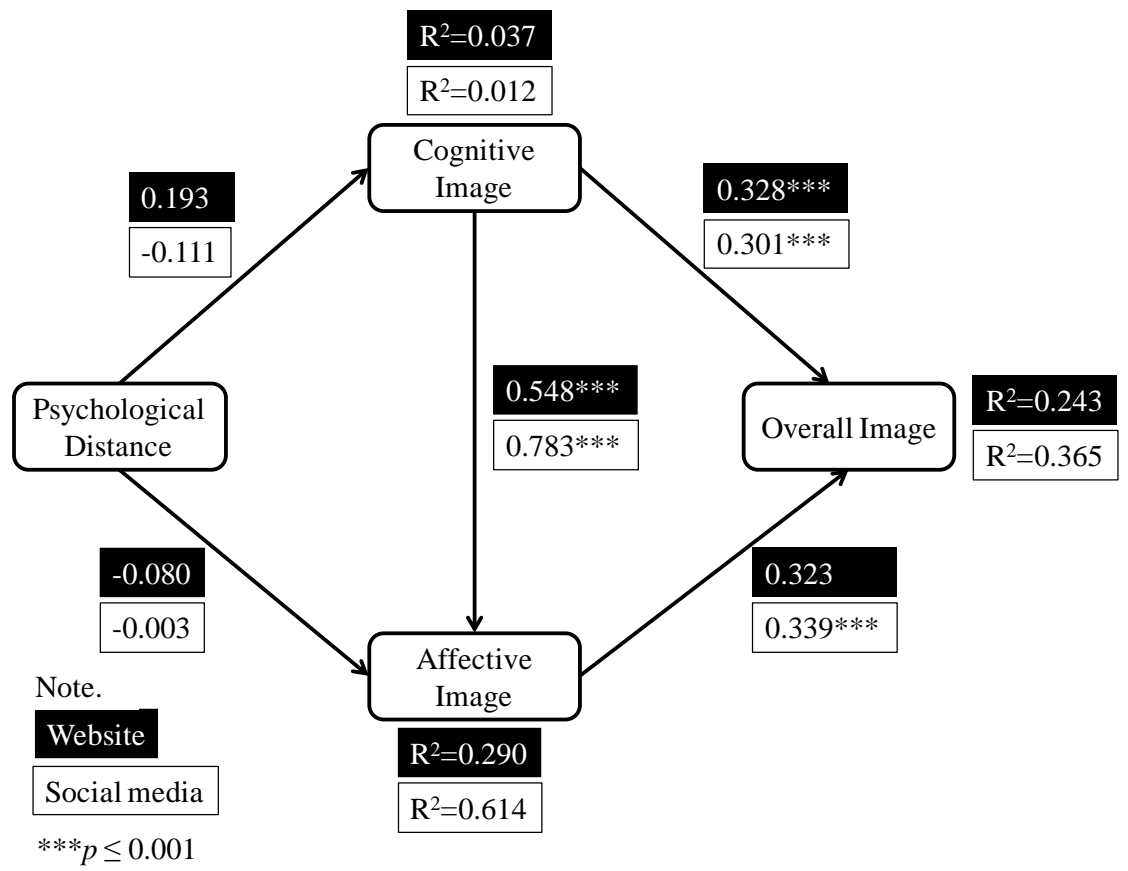

Source: Authors.

Regarding the model discussing official websites, this study finds both relevant and significant relationships between the cognitive image and the affective image variables and also, a relationship between the cognitive image and overall destination image variables. On the other hand, regarding the model discussing social media, this study finds an additional and significant relationship besides of the ones already stated: the relationship between the affective image and the overall destination image variables, thus supporting suggested hypotheses in the available literature proposing that the overall destination image variable is influenced by both affective image and cognitive image variables. In this regard, this study also concludes that the overall destination image variable, when assessed in a model where social media are the main source of information, is more comprehensively approached by integrating in the model the effects of the cognitive and affective dimensions, resulting in a higher $\mathrm{R}^{2}$ value as opposed to the value obtained using the model where official websites are the main source of information.

\section{Discussion and conclusions}

As Marlow and Dabbish (2014) stated, even if DMOs make a wide use of official websites and social media, the influence of said online platforms need to be addressed in a more comprehensive way regarding the destination image. This research enriches knowledge about the destination image formation process, taking into account the impact of the psychological distance variable and the moderating effect of the sources of online information approached by tourists (official websites and social media).

These findings show that the psychological distance variable does not impact the image of the tourist destination nowadays. In addition, the overall destination image variable is estimated in a more reliable way when tourists approach social media as the main source of information.

In light of these findings, this study concludes that the cognitive image variable positively influences affective image and this relationship in turn positively impacts the overall destination image variable, verifying results from previous studies (Baloglu \& McCleary, 1999; Kim \& Stepchenkova, 2015; Lin et al., 2007; Mano \& da Costa, 2015; Tan \& Wu, 2016). The relationships were validated within the total sample used for data collection (official websites and social media). Results of this research also show that the greater influence of the cognitive image variable over the overall image variable becomes apparent. Also, the impact of the 
cognitive image variable is indirectly and positively influenced by the affective image variable, which is in turn positively influenced by the cognitive variable.

The proposed relationships between the psychological distance construct and the cognitive and affective images were not supported. Unexpectedly, the psychological distance construct does not negatively impact the way tourists form their cognitive and affective images. This finding is a significant contribution of this research since previous studies (e.g. Chen et al., 2013; Marlow \& Dabbish, 2014; San Martin \& Rodriguez del Bosque, 2008) suggested that the psychological distance construct negatively influences the overall destination image. The reasoning behind this finding is that nowadays tourists can access a great volume of information anytime thanks to internet, they have become accustomed to analyze said information and they are less removed from the traits of different foreign cultures. All these facts might lead to overcome the effect of the psychological distance and they might no longer impact the destination image formation process. However, this finding needs to be approached with certain caution given the distinctiveness of the sample used in this study (this is, young population with a high level of education, accustomed to properly analyze information available in internet and not especially unfamiliar with different cultures among other factors).

In regard of the moderating effect of the sources of online information, this study shows different impacts of the cognitive image on the affective image: when social media are involved then the influence of the cognitive image is vastly greater. In addition, the positive impact of the affective image on the overall image only becomes of relevance when social media are involved in the image formation process as opposed to official websites. Thus, thanks to social media, the cognitive and affective images largely and directly influence the overall perceived image of the destination. This finding enriches the knowledge about the influences of the official websites and social media on the destination image formation process since up to this date literature focused in the overall impact of the information platforms (Kladou \& Mavragani, 2015; Költringer \& Dickinger, 2015; Llodra-Riera et al., 2015; Lyu, 2016) without resorting to contrast the different influence in the image formation process when said platforms are managed by the DMO.

Traditionally, DMOs have approached official websites as the main source of relevant information served to potential tourists. This information includes pictures, videos and recommendations among others. Cognitive information items such as infrastructures, tidiness, safety, comfort or overcrowding have a distinct influence on the perceived image of the destination. In light of this, cognitive information should be made available in a friendly and attractive way so users can easily analyze it thanks to the use of pictures. Similarly, affective items such as enjoyment, leisure, excitement, sense of adventure and others also impact the overall destination image, especially when social media are involved. In this regard, it is important to note that, since social media became widely spread, DMO have lost a certain degree of control over the information served to potential tourists since they are already playing a key role sharing their experiences in social media. In order to keep control over the available information about the overall destination image, DMOs not only need to effectively manage and maintain their official website, they also need to publish the information in social media. The aim is to help tourists rely on the available information and making them prone to contribute the image formation process, be it in activities suggested by the DMO or by other users. Information should be shared and made available to all users in a friendly, attractive way.

This study also shows some limitations. Firstly, even if sampling groups in this research include a number of participants higher than the minimum recommended according to research criteria, the samples only include college students, therefore results of this research are not transposable, they cannot be used to discuss researches where the used sample is not similar. In addition, the destination choice is a far and unfamiliar place in the eyes of most participants in the sample, constraining the validity of the model and pointing to other variables to be taken into account when tourists already know the destination or it feels more familiar to them. Lastly, even if several social media were involved in this research, some others were left aside which also notably influence tourists such as ranking websites (such as Tripadvisor, Booking, etc.). Finally, this study is considered transversal so it does not analyze the evolution of sample results over time.

Future lines of investigation could use a larger sample with different types of participants by including different profiles of tourists. Also, future researches could estimate and assess the effect of every type of social media separately as opposed of a unique entity as considered in this paper, assessing the influence of online platforms where the DMO might interact without retaining control and also ranking websites. With this approach, it would result valuable trying to test the suggested model in tourism destinations already known and visited or those which feel more familiar to users. Finally, other variables such as tourists' experience and involvement in both travels and online environments could be included into the model proposed in this paper.

\section{References}

Agapito, D., Valle, P. O., \& Mendes, J. C. (2013). The Cognitive-AffectiveConative Model of Destination Image: A Confirmatory Analysis. Journal of Travel \& Tourism Marketing, 30(5), 471-481.

AIMC (2015). 170 Navegantes en la Red. Encuesta AIMC a usuarios de Internet 2014. Retrieved February 26, 2015, from http://www.aimc.es/Navegantes-en-la-Red-.html.

Avraham, E. (2015). Destination image repair during crisis: Attracting tourism during the Arab Spring uprisings. Tourism Management, 47, 224232.

Ayeh, J. K., Au, N. \& Law, R. (2013). Predicting the intention to use consumer-generated media for travel planning. Tourism Management, 35, 132-143.

Baloglu, S. \& McCleary, K. W. (1999). A model of destination image formation. Annals of Tourism Research, 26(4), 868-897.

Barclay, D., Higgins, C. \& Thompson, R. (1995). The Partial Least Squares (PLS) Approach to Causal Modeling: Personal Computer Adoption and Use an Illustration. Technology Studies, 2(2), 285-309.

Beerli, A. \& Martin, J. D. (2004). Factors influencing destination image. Annals of Tourism Research, 31(3), 657-681.

Chen, H. J., Chen, P. J. \& Okumus, F. (2013). The relationship between travel constraints and destination image: A case study of Brunei. Tourism Management, 35, 198-208

Chin, W. W. (1998). The partial least squares approach for structural equation modeling. In G. A. Marcoulides (Ed.), Modern methods for business research (pp. 295-236). London: Lawrence Erlbaum Associates 
Choi, S., Lehto, X. Y. \& Morrison, A. M. (2007). Destination image representation on the web: Content analysis of Macau travel related websites. Tourism Management, 28(1), 118-129.

Chung, N., Lee, H., Lee, S. J. \& Koo, C. (2015). The influence of tourism website on tourists' behavior to determine destination selection: A case study of creative economy in Korea. Technological Forecasting and Social Change, 96, 130-143.

Crompton, J. L. (1979). An assessment of the image of Mexico as a vacation destination and the influence of geographical location upon that image. Journal of Travel Research, 17(4), 18-23.

Cronbach, L. J. (1951). Coefficient alpha and the internal structure of tests. Psychometrika, 22(3), 297-334.

Del Vasto-Terrientes, L., Fernández-Cavia, J., Huertas, A., Moreno, A. \& Valls, A. (2015). Official tourist destination websites: Hierarchical analysis and assessment with ELECTRE-III-H. Tourism Management Perspectives, $15,16-28$.

Dichter, E. (1985). What is in an Image? Journal of Consumer Marketing, 2, 39-52.

Driscoll, A., Lawson, R. \& Niven, B. (1994). Measuring tourists' destination perceptions. Annals of Tourism Research, 21(3), 499-511.

Falk, R. F. \& Miller, N. B. (1992). A Primer for Soft Modeling. University of Akron Press, Akron.

Fernández-Cavia, J., Rovira, C., Díaz-Luque, P. \& Cavaller, V. (2014). Web Quality Index (WQI) for official tourist destination websites. Proposal for an assessment system. Tourism Management Perspectives, 9, 5-13.

Fornell, C., \& Larcker, D. F. (1981). Evaluating structural equation models with unobservable variables and measurement error. Journal of Marketing Research, 18(1), 39-50.

Fotis, J., Buhalis, D. \& Rossides, N. (2012). Social media use and impact during the holiday travel planning process. In M. Fuchs, F. Ricci, \& L. Cantoni (Eds.), Information and communication technologies in tourism (pp. 13-24). Vienna, Austria: Springer-Verlag.

Frías-Jamilena, D. M., Rodríguez-Molina, M. A. \& Castañeda-García, J. A. (2008). Internet vs. travel agencies on pre-visit destination image formation: An information processing view. Tourism Management, 29(1), 163-179.

Gartner, W. C. (1994). Image Formation Process. Journal of Travel \& Tourism Marketing, 2(2-3), 191-216.

Hair, J. F., Sarstedt, M., Hopkins, L., \& Kuppelwieser, V. G. (2014). Partial least squares structural equation modeling (PLS-SEM): An emerging tool in business research. European Business Review, 26(2), 106-121.

Hays, S., Page, S. J. \& Buhalis, D. (2013). Social media as a destination marketing tool: its use by national tourism organisations. Current issues in Tourism, 16(3), 211-239.

Henseler, J. (2007). A new and simple approach to multi-group analysis in partial least squares path modeling. In: Martens, Harald, Næs, \& Tormod (Eds.). Proceedings of PLS'07-The 5th International Symposium on PLS and Related Methods (pp. pp. 104-107). Ås, Norway, September 5-7.

Henseler, J., Ringle, C. M. \& Sarstedt, M. (2015). A New Criterion for Assessing Discriminant Validity in Variance-based Structural Equation Modeling. Journal of the Academy of Marketing Science, 43(1), 115-135.

Jeong, C., Holland, S., Jun, S. H. \& Gibson, H. (2012). Enhancing destination image through travel website information. International Journal of Tourism Research, 14(1), 16-27.

Josiassen, A., Assaf, A. G., Woo, L., \& Kock, F. (2015). The Imagery-Image Duality Model: An Integrative Review and Advocating for Improved Delimitation of Concepts. Journal of Travel Research. Advance online publication. Doi: 10.1177/0047287515583358.
Kim, H. \& Stepchenkova, S. (2015). Effect of tourist photographs on attitudes towards destination: Manifest and Latent content. Tourism Management, 49, 29-41.

Kim, S. B., Kim, D. Y. \& Wise, K. (2014). The effect of searching and surfing on recognition of destination images on Facebook pages. Computers in Human Behavior, 30, 813-823.

Kladou, S. \& Mavragani, E. (2015). Assessing destination image: An online marketing approach and the case of TripAdvisor. Journal of Destination Marketing \& Management, 4, 87-193.

Költringer, C. \& Dickinger, A. (2015). Analyzing destination branding and image from online sources: A web content mining approach. Journal of Business Research, 68, 1836-1843.

Konecnik, M. \& Gartner, W. C. (2007). Customer-based brand equity for a destination. Annals of tourism research, 34(2), 400-421.

Liberman, N., Trope, Y. \& Stephan, E. (2007). Psychological distance. In A. W. Kruglanski \& E. T. Higgins (Eds.), Social Psychology. Handbook of Basic Principles (2nd Ed.) (pp. 353-381). New York: The Guilford Press.

Lim, Y., Chung, Y. \& Weaver, P. A. (2012). The impact of social media on destination branding: consumer-generated videos versus destination marketer-generated videos. Journal of Vacation Marketing, 18(3), 197 206.

Lin, C. H., Morais, D. B., Kerstetter, D. L. \& Hou, J. S. (2007). Examining the role of cognitive and affective image in predicting choice across natural, developed, and theme-park destinations. Journal of Travel Research, 46(2), 183-194.

Llodrà-Riera, I., Martínez-Ruiz, M. P., Jiménez-Zarco, A. I. \& IzquierdoYusta, A. (2015). A multidimensional analysis of the information sources construct and its relevance for destination image formation. Tourism Management, 48, 319-328.

Lyu, S. O. (2016). Travel selfies on social media as objectified selfpresentation. Tourism Management, 54, 185-195.

MacKay, K. J. \& Fesenmaier, D. R. (1997). Pictorial element of destination in image formation. Annals of Tourism Research, 24(3), 557-565.

Mano, A. \& da Costa, R. A. (2015). A conceptual model of the antecedents and consequences of tourist destination image. Procedia Economics and Finance, 23, 15-22.

Mariani, M. M., Di Felice, M. \& Mura, M (2016). Facebook as a destination marketing tool: Evidence from Italian Regional Destination Management Organizations. Tourism Management, 54, 321-343.

Marlow, J. \& Dabbish, L. (2014). When is a picture not worth a thousand words? The psychological effects of mediated exposure to a remote location. Computers in Human Behavior, 30, 824-831.

Massara, F. \& Severino, F. (2013). Psychological distance in the heritage experience. Annals of Tourism Research, 42, 108-129.

Moura, F. T., Gnoth, J. \& Deans, K. R. (2014). Localizing Cultural Values on Tourism Destination Websites: The Effects on Users' Willingness to Trave and Destination Image. Journal of Travel Research, 12, 528-542.

Munar, A. M. \& Jacobsen, J. K. S. (2014). Motivations for sharing tourism experiences through social media. Tourism Management, 43, 46-54.

Myers, J. G. (1968). Consumer Image and Attitude. Berkeley: Institute of Business and Economic Research, University of California, Berkeley.

Ng, S. I., Lee, J. A. \& Soutar, G. N. (2007). Tourists' intention to visit a country: The impact of cultural distance. Tourism Management, 28(6), 1497-1506.

Nunnally, J. C., \& Bernstein, I. H. (1994). Psychometric theory (3rd ed.). New York: McGraw-Hill. 
Prentice, R. (2004). Tourist familiarity and imagery. Annals of Tourism Research, 31(4), 923-945.

Ringle, C. M., Wende, S., \& Becker, J.-M. (2015). SmartPLS 3. Bönningstedt: SmartPLS.

Rodríguez-Molina, M. A., Frías-Jamilena, D. M, \& Castañeda-García, J. A. (2015). The contribution of website design to the generation of tourist destination image: The moderating effect of involvement. Tourism Management, 47, 303-317.

San Martín, H. \& Rodríguez del Bosque, I. A. (2008). Exploring the cognitiveaffective nature of destination image and the role of psychological factors in its formation. Tourism Management, 29(2), 263-277.

Smith, A. N., Fischer, E. \& Chen, Y. (2012). How Does Brand-related Usergenerated Content Differ across YouTube, Facebook, and Twitter? Journal of Interactive Marketing, 26(2), 102-113.

Smith, W. W., Li, X. R., Pan, B., Witte, M. \& Doherty, S. T. (2015). Tracking destination image across the trip experience with smartphone technology. Tourism Management, 48, 113-122.

Stepchenkova, S. \& Zhan, F. (2013). Visual destination images of Peru: Comparative content analysis of DMO and user-generated photography. Tourism Management, 36, 590-601.

Tan, W. K. \& Wu, C. E. (2016). An investigation of the relationships among destination familiarity, destination image and future visit intention. Journal of Destination Marketing \& Management, (Advance online publication), doi:10.1016/j.jdmm.2015.12.008.

Tasci, A. D. \& Gartner, W. C. (2007). Destination image and its functional relationships. Journal of travel research, 45(4), 413-425.

Trope, Y., Liberman, N. \& Wakslak, C. (2007). Construal Levels and Psychological Distance: Effects on Representation, Prediction, Evaluation, and Behavior. Journal of Consumer Psychology, 17(2), 83-95

Tseng, C., Wu, B., Morrison, A. M., Zhang, J. \& Chen, Y.-C. (2015). Travel blogs on China as a destination image formation agent: A qualitative analysis using Leximancer. Tourism Management, 46, 347-358.

Walmsley, D. J. \& Young, M. (1998). Evaluative images and tourism: The use of personal constructs to describe the structure of destination images. Journal of Travel Research, 36(3), 65-69.

Xiang, Z. \& Gretzel, U. (2010). Role of social media in online travel information search. Tourism Management, 31(2), 179-188.

Xiong, J., Hashim, N. H. \& Murphy, J. (2015). Multisensory image as a component of destination image. Tourism Management Perspectives, 14, 34-41.

Zhang, J., Seo, S. \& Lee, H. (2013). The impact of psychological distance on Chinese customers when selecting an international healthcare service country. Tourism Management, 35, 32-40.

Received: 14 May 2016

Revisions required: 07 July 2016

Accepted: 04 January 2017 